\title{
Promotion of Students Participation and Academic Achievement in Large Classes: An Action Research Report
}

\author{
Sumathi Kumaraswamy \\ Dr., College of Business Administration University of Bahrain, Bahrain, \\ skumaraswamy@uob.edu.bh
}

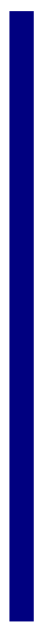

\begin{abstract}
Businesses and employers look for graduates who could collaborate and work effectively in team projects. Consequently, it is important to introduce, train and develop collaborative skills in students at different levels to prepare them to meet the labour market needs. This action research introduced group activity in finance course to improve the students' participation and their academic achievement through group activities. The results of observation indicated that the students' participation increased with group activity strategy. The increased students' participation had an impact on their academic achievement. The empirical results clearly indicated that the average scores of students had increased from 2.75 to 7.24 after the introduction of group activities. The students also well perceived the group activity strategy as they found it interesting and useful and it had changed the way they learned the course. The empirical results of Factor analysis identified the core factor that influenced student's participation through group activities was greatly influenced by the peers included in each group. In a nutshell, group activity strategy has proved effective and successful in promoting student participation and academic achievement in large classes.
\end{abstract}

Keywords: students' participation, students' academic achievement, group activity, large classes, achievement

\section{INTRODUCTION}

Large class teaching is not a new phenomenon though, it attracts the attention of the educators in the recent past and has turned into reality and a common situation. There is a wide array of ideas on what or how many students constitutes a "large class". According to the National Center for Education Statistics 2016-17, the average class size is 26 students. Notwithstanding the average size, the number of students in many of the business colleges are steadily increasing in the recent past. Many factors drive the size of the increase in class size: globalization, increasing population, insufficient teaching staff, lack of physical space, budgetary constraint, unexpected high enrolment and the like (Marcus 1997). Even though a large diversity of teaching tools are now

Citation: Kumaraswamy, S. (2019). Promotion of Students Participation and Academic Achievement in Large Classes: An Action Research Report. International Journal of Instruction, 12(2), 369-382. https://doi.org/10.29333/iji.2019.12224a 
available, large class teaching still has a significant role to play in higher education (Zhang 2005). A substantial increase in the enrolment figures at the university level, particularly in business colleges creates not only challenges but also a lot of opportunities in developing the teaching-learning environment. Promoting effective learning and student engagement are always challenging in any class, which is explicitly strenuous for instructors of large classes. Some of the common problems faced by instructors in large classes could be one or more of the following:

- The classroom management could be highly strenuous; high noise, late arrivals, early leavers, sleepy and non-motivated students, lack of individual attention to weak students and the like.

- The dominance of proficient students in the first few rows makes lower level ones to feel alienated. Few other students feel shy to share their ideas and develop reluctance in communicating or sharing their ideas.

- Large classes encourage passive students at higher levels, less or no interaction with peers and with the instructor, which affects the students' overall academic achievement.

In a nutshell, large classes impose challenges to the instructors in achieving the course intended learning outcomes successfully. Consequently, most teachers find large class teaching a "performance" with the increased likelihood of stage fright (Biggs and Tangs, p.153). As highlighted by Biggs and Tangs (p.22) on the theories of Constructivism and Phenomenography after all teaching is not a matter of transmitting knowledge but of engaging students in active learning. A course instructor initially could be comfortable with a set of prepared notes, presentations, and exams and over the course of time, the monotonous teaching style might create boredom.

Felt the same way, the researcher realized that it's time to effectively provoke students' participation in large classes by developing management strategies that were quite different from those appropriate to small classes while classes with above 65 students were assigned. So, this action research was developed to find appropriate methods of teaching in promoting students participation in large classes for a better understanding of the concepts and to reflect their understanding of their exams. Works of literature quote many strategies in managing large classes including a round, buzz groups, and brainstorming, using video, case study material, demonstrations, role plays, tests, storytelling, goldfish bowl, take a minute, in-class project work, pair or group work and the like (Brenda Smith, Susan, Larkin Hood, David Hortin).

Of the various strategies, group activity found to be the most appropriate for the sample course. The reasons being the large number of students, limited time, and the course material had many numerical problems solving with decision-making exercises which requires the active participation of students. Group work provides an opportunity for the learners to learn from each other which makes them as active learners. There have been previous studies highlighting group work as a predominant strategy in improving students' participation in large classes (Zhang, Zhenhui, and Smith). Also, the kinds of literature gave the researcher an insight that teaching strategies like (take a minute, buzz 
groups, tests, using videos) could be incorporated into group activity to make the groups more active. Through group activity strategy in large classes, it was envisaged that the students will be active learners as they will engage in hands-on activities, interact, investigate and interpret. Given this background this action research was undertaken to improve students' participation by introducing group activity strategy in large classes of investment management course. In addition, an attempt is made to identify whether the group activity strategy promotes the students' academic grades in large classes.

\section{REVIEW OF LITERATURE}

Volumes of literature are available on how to manage large classes and improve classroom participation and few research reports on the impact of group activity to improve the student participation in large classes.

Renaud, Tannenbaum, and Stantial (2007) point out that in large classes there are always enough students to interact and the teacher in large classes never feel bored as they find new strategies to cope as it happened with me.

Smith, K (2000) suggested a range of strategies that involve massive reorganization of large classes into formal small group learning. The successful experience of many faculty members on different strategies that made them redesign their large classes to center around small group learning was compiled in this study.

An exploratory study by Carpenter (2006) similar to Smith, K (2000) in identifying the effective teaching method for large class environment concluded that students prefer any teaching method that makes them active learners, engaging in discussion rather than passively listening to a lecture.

An attempt by Tesfaye (2015) to improve second-year tourism management students' participation in active learning methods found that $75 \%$ of the students assured that group discussion gave them more chance to participate freely in the class.

Zhang (2005) implemented a simple and a practical action research that developed a successful interactive culture in the class through group activities. The action research was very well planned and executed with a small change in each phase in introducing the activities to the students gradually and clearly.

In contrast, an action research by Kasa (2016) on chemistry students at Assosa University identified the possible reasons for the low participation of the students in groups. Inactive teaching methods used by the teachers, seating arrangements, fear of incorrect answers, own personal fears of feeling inadequate in front of others students and teachers were some of the reasons made the students not to participate.

Zhenhui (2001) in his study about the advantages of group-centered learning in large classes' stresses the need of shift to student-centered learning from teacher-centered classroom teaching worldwide. The author highlights that group works creates more opportunities for interaction, it enables the students to plan and evaluate their learning and also it facilitates cooperation among students. Since the group activities facilitates 
student centered learning wherein the students discuss, explore, debate and arrive at common conclusions within their groups.

Similar results were achieved by Smith (2000) Zhang (2005), Tesfaye (2015), Taqi and Al-Nouh (2014) and Poutos (2016).

A similar study and results by Taqi and Al-Nouh (2014) recommended the instructors in higher education try to find a slot or two for group work in the syllabus and to bring a positive change in the students learning attitude.

In a recent study, Sofroniou and Poutos (2016) investigated the effectiveness of group work in mathematics course and highlighted that group work allowed students to develop a range of skills. It develops their critical thinking, analytical and communication skills; effective teamwork; appreciation and respect for other views, techniques, and problem-solving methods, all of which promote active learning and enhance student learning.

While most of the previous research studies on group activities were focused on language classes, this action research made an attempt to explore the effect of the same in an advanced finance course to fill the gap in the literature. The most significant reason for making use of large group teaching is to give whole cohorts of learners shared experience so that each learner feels part of the class (Race, 2014, p.164). This study considers the improvement in students' participation as the independent variable and the academic achievement as the dependent variable. 128 students enrolled in two sections (one with 68 and other section with 60 students) during the academic year 2016-2017 participated in the study. Students had a prior knowledge about financial management enrolled for this course and also students from other specialization chose this course as elective. So, there were different levels of students within one large class intended to achieve the same learning outcomes.

\section{RESEARCH QUESTIONS}

The following research questions were framed based on the theoretical base and rationale of the study:

1. How effectively can the introduction of group activity strategy promote student's participation in large classes?

2. To what extent the group activity strategy enhances students' academic achievement in large classes?

How do students view the group activity strategy as a helpful way for them in large classes?

\section{METHOD}

\section{Data Collection Tools}

To validate the research results, a triangulation of data collection methods was utilized. The term triangulation stands for the procedure that entails carrying out three measurements to determine the exact position of a point in the landscape. (Meijer 2002) 
Observation, questionnaire and test results were used to gather the answer for the research questions. Similar data collection instrument used by Taqi and Al-Nouh (2014) is one of the key sources of this research design.

\section{Observation}

After reviewing similar previous studies (Zhang 2005; Taqi and Al-Nouh 2014; Kasa 2016) an observation checklist was developed and used to capture the level of participation of students. The checklist contained various factors representing students' active engagement and interaction.

\section{Questionnaire}

The Questionnaire is the second data source containing six parts with closed, open end and rating scale questions. The first part of the questionnaire included the participant's personal profile, second part captured their attitude towards group activity. 5 Likert scale questions were used to third, fourth and fifth part to measure the participant's perception towards their learning experience through group activity, the role of the instructor in managing the groups, and about their peers within their groups. Last part consisted of comments and suggestions from the participants. The questionnaire was administered and collected during the class after completing Cycle 2. The questionnaire was mainly adapted from Sofroniou (2016), Zhang (2005), Taqi and Al-Nouh (2014) and Dowson, F and Dowson, M (2009) studies.

\section{Test grades}

Two test grades were used to measure the student's academic achievement. Test 1 was administered after completing the precycle and test 2 at the end of cycle 2 . Similar data collection instruments were used by Taqi and Al-Nouh (2014). Both the tests were conducted for 60 minutes with similar question patterns that included 10 multiple choice questions and 3 problem solving questions.

\section{Research Procedures:}

This action research is based on two consecutive cycles: Cycle 1 and Cycle 2 and a precycle before cycle 1 . The detailed flow of cycles is presented below in Figure 1.

\begin{tabular}{|l|l|}
\hline Precycle & $\cdot$ Use lecturing as a teaching method 1 \\
\hline Cycle 2 & $\cdot$ Forming groups by the instructor \\
\hline
\end{tabular}

Figure 1

Action Research Cycles

Precycle: Use lecturing as a method of teaching 
The precycle classes continued for 150 minutes per week constituting 50 minutes class for three days(UTH - Sunday, Tuesday and Thursday) for two weeks. During this precycle, the traditional style of teaching by giving lectures in the classroom was employed using a multimedia projector to project the slides, and solving and explaining the problems on the whiteboard and asked the students to copy the answers. A checklist was used to observe the student's participation and test1 to measure their academic achievement was administered at the end of precycle.

\section{Cycle 1: Forming groups by the instructor}

As argued by Biggs and Tangs (2003) quoted in Kasa (2016) the learning process depends on the level of student-student interaction and student-teacher interaction in a conducive learning environment. The formation of appropriate interactive groups and the effective use of materials with clear instructions are essential tools in the teachinglearning process (Kasa, 2016).

Realizing the importance of the above-said factors, groups were formed with 6 members based on one of the types proposed by Hassanien (2007) quoted in Taqi and Al-Nouh (2014). After precycle grades the weak students were coupled with proficient ones to facilitate better learning and interaction in the group. Participants were asked to arrange themselves in a semi-circle curve to facilitate interaction with peers and the instructor. Cycle 1 continued for a duration of two weeks similar to precycle.

As insisted by Burke (2011) merely assigning a group does not itself create critical thinking outcomes. So, a couple of hands-on activities were developed and used during Cycle 1 and Cycle 2 to make the students more active.
1. Icebreaker Activity
2. Using Visual Aids
3. Using Videos
4. Problem Solving
5. Decision-making exercises
6. Portfolio construction
7. Short quizzes

Students' level of interaction and participation during these activities were recorded using an observation checklist 2. Clear instructions were given to students on how they were expected to act within their groups and respond to the activities given to them. After completing the first cycle, oral and written feedbacks were given with explanations and suggestions for improvement to each group.

\section{Cycle 2: Forming groups by the students}

At the end of cycle 1, it was observed that the students were used to the group activities and the interaction among their peers was high, including personal discussions. To bring back the rapport, the students were asked to form different groups of their choice. Since some students showed reluctance in changing the groups were explained about the importance of expanding their interaction and not to restrict them within the same group. 
Few other students were happy as they could form groups with their friends and it was observed that their performance was relatively better than other groups recalled the work of Hendry and Davy (2005) quoted in Taqi and Al-Nouh (2014). He highlighted that groups formed by friends have excellent relationships as they respect each other, accept criticism from one another and listen to each other. Cycle 2 continued for a duration of two weeks similar to other cycles. Similar to precycle, a formative assessment was given to students with feedback for improvement after completing Cycle 2. In addition, a questionnaire was distributed in class to measure their perception on the group activities in Investment management course.

\section{FINDINGS AND DISCUSSION}

A detailed presentation of the major finding from the observation checklist to observe the student's participation levels, test results to measure their academic achievement and filled in questionnaires to captures their learning experience through group activities are presented below.

\section{Students' participation level in large classes (Data source: Observation checklist)}

The results of the observation indicated that the number of students who actively engaged in class has considerably increased in cycle 1 and 2 compared to precycle as shown in Table 1 . The ratios are calculated by the number of students participated to the number of students attended.

Table 1

Students' Participation Level in Large Classes

\begin{tabular}{llll}
\hline & Precycle & Cycle 1 & Cycle 2 \\
\hline Actively Engaged Students. & $59 \%$ & $94 \%$ & $97 \%$ \\
\hline Students interacting with peers. & $9 \%$ & $95 \%$ & $85 \%$ \\
\hline Students interacting with the instructor. & $10 \%$ & $64 \%$ & $89 \%$ \\
\hline
\end{tabular}

These findings are similar to the results of Zhang's (2005) study but contradictors Kasa's (2016) action research. Only 59\% of the students were actively engaged during the precycle. This was measured by the number of students who are actively listening during the lecture, bringing relevant materials to classes, taking notes and solving the answers. At that point, recalled by the words of Race (2014, p.177), "Making learning happen not by lecturing" some activities were developed to make students active in class and the results were reflected in 94\% engagement in Cycle 1 and 97\% in Cycle 2.

As precycle involved the lecturing style of teaching, the number of interactions with peers was very low. The chances for interaction with the peers are created through the activities in cycle 1 and 2 . The activities involved very limited time which motivated them to split their work and present one answer representing their group. This created an environment for the students to interact and learn from each other. In cycle 2, the number of interactions decreased surprisingly and the possible reasons could be the change in group formation. Some of the students also expressed their unwillingness to change the group as they felt comfortable within the formed groups. These results were 
contradictory to the results of Zhang (2005) as the number of interactions among students was stable in his study.

The percentage of students initiating the interaction with the instructor were high in cycle 2 compared to precycle that few students were hesitant to initiate discussion with me. Inspired by the words of Brooks (1984) stating that popular lecturers are clear, tell good jokes, respect the class as they take learning as serious, the researcher applied similar strategies. To increase the number of interactions the researcher tried to make the students feel comfortable in the class by telling jokes, providing positive quotes, motivated the students for their simple answers by thanking them, corrected their mistakes smoothly, and stayed after the class time for few minutes to clear their doubts and the like. Eventually, all these efforts accelerated the number of interactions in the class.

\section{Students' Academic achievement (Data source: Test grades)}

To measure the objective of to what extent the group activity strategy enhances student's academic achievement in large classes, Paired t-test was administered with two repeated measure variables. The variables are the average test score of the students before and after the introduction of group activity. The results are presented in Table 2

Table 2

Difference in Students' Average Test Scores

\begin{tabular}{|c|c|c|c|c|c|c|c|c|c|}
\hline \multicolumn{10}{|c|}{ Paired Samples Statistics } \\
\hline & & \multicolumn{2}{|c|}{ Mean } & \multicolumn{2}{|r|}{$\mathrm{N}$} & \multicolumn{2}{|c|}{ Std. Deviation } & \multicolumn{2}{|c|}{ Std. Error Mean } \\
\hline \multirow[t]{7}{*}{ Pair 1} & Test 1 & \multicolumn{2}{|c|}{2.7500} & \multicolumn{2}{|r|}{128} & \multicolumn{2}{|c|}{1.23594} & \multicolumn{2}{|c|}{.10924} \\
\hline & Test 2 & \multicolumn{2}{|c|}{7.2422} & & 128 & \multicolumn{2}{|c|}{1.95921} & \multicolumn{2}{|c|}{.17317} \\
\hline & & \multicolumn{6}{|c|}{ Paired Differences } & \multirow[b]{5}{*}{ df } & \multirow{5}{*}{$\begin{array}{l}\text { Sig. (2- } \\
\text { tailed) }\end{array}$} \\
\hline & & \multirow[t]{4}{*}{ Mean } & \multirow{4}{*}{$\begin{array}{l}\text { Std. } \\
\text { Deviation }\end{array}$} & Std. & \multirow{3}{*}{\multicolumn{2}{|c|}{$\begin{array}{l}95 \% \text { Confidence } \\
\text { Interval of the } \\
\text { Difference }\end{array}$}} & \multirow[b]{4}{*}{$\mathrm{t}$} & & \\
\hline & & & & Error & & & & & \\
\hline & & & & \multirow[t]{2}{*}{ Mean } & & & & & \\
\hline & & & & & Lower & Upper & & & \\
\hline Pair 1 & $\begin{array}{l}t 1- \\
t 2\end{array}$ & -4.4921 & 1.5673 & .13854 & -4.76633 & -4.21805 & -32.426 & 127 & .000 \\
\hline
\end{tabular}

The outputs clearly indicate that there is enough evidence to suggest that the average scores of students have increased from 2.75 to 7.25 after the introduction of group activities. The mean scores are statistically significant as the p values are less than $0.01 \%$ level of significance. Thus, the null hypothesis is rejected and the alternate hypothesis that there is a significant difference in the mean scores of students after the introduction of group activity in large classes is accepted.

Students' attitude towards group activities (Data source: Questionnaire)

Primary data was collected through a structured questionnaire from 97 students having 19 criteria explaining the students' attitude towards group activities in large classes were loaded in SPSS for initial analysis. Exploratory Factor Analysis (EFA) has been applied to identify the underlying factor that promotes student's participation in large classes by identifying the variables with high inter-correlation. As an initial step to proceed with factor analysis, the test of the validity of data has been done with the help of Kaiser- 
Meyer-Olkin (KMO) Measure of Sampling Adequacy and Bartlett's test of sphericity. The criterion for accepting the factor is fixed as a minimum of 1.00 as its Eigen value. The results are shown in Table 3 below.

Table 3

KMO and Bartlett's Test

\begin{tabular}{lll}
\hline Kaiser-Meyer-Olkin Measure of Sampling Adequacy. & .839 \\
\hline Bartlett's Test of Sphericity & Approx. Chi-Square & 916.594 \\
\cline { 2 - 3 } & df & 171 \\
\cline { 2 - 3 } & Sig. & .000 \\
\hline
\end{tabular}

Normally, $0<\mathrm{KMO}<1$ and if $>0.5$, the sample is adequate. Since the resultant KMO value is at $0.839>0.5$, it is confirmed that the sample is adequate to proceed with the factor analysis. The Bartlett's test of sphericity is used to experiment the null hypothesis of no statistically significant relationship between the variables affecting the student's participation in large classes. The approximate Chi-square is 916.594 with 171 degrees of freedom is statistically significant at $0.01 \%$ level of significance. Thus, the null hypothesis is rejected and it is accepted that there is a significant interrelationship between variables. Consequently, these two measures set the minimum standards for further analysis.

\section{Eigen values and Total variance explained}

With sample adequacy, factor analysis as a further step extracts 17 factors initially with 17 input variables as shown in Table 6.2. The quality score of each component called as Eigen value are likely to represent the underlying factor. From Table 4 it can be visualized that the first five components have Eigen values greater than 1, directing to a conclusion that the 17 variables seem to measure five underlying factors. In addition, these five factors are considered as "strong factors" in influencing the students' attitude towards group activities.

Table 4

Eigen Values and Total Variance Explained

\begin{tabular}{|c|c|c|c|c|c|c|c|c|c|}
\hline \multirow{2}{*}{ Component } & \multicolumn{3}{|c|}{ Initial Eigen values } & \multicolumn{3}{|c|}{$\begin{array}{l}\text { Extraction Sums of Squared } \\
\text { Loadings }\end{array}$} & \multicolumn{3}{|c|}{$\begin{array}{l}\text { Rotation Sums of Squared } \\
\text { Loadings }\end{array}$} \\
\hline & Total & $\begin{array}{l}\% \text { of } \\
\text { Variance }\end{array}$ & $\begin{array}{l}\text { Cumulative } \\
\%\end{array}$ & Total & $\begin{array}{l}\% \text { of } \\
\text { Variance }\end{array}$ & $\begin{array}{l}\text { Cumulative } \\
\%\end{array}$ & Total & $\begin{array}{l}\% \text { of } \\
\text { Variance }\end{array}$ & $\begin{array}{l}\text { Cumulative } \\
\%\end{array}$ \\
\hline 1 & 7.381 & 38.847 & 38.847 & 7.381 & 38.847 & 38.847 & 3.78 & 19.896 & 19.896 \\
\hline 2 & 1.677 & 8.825 & 47.672 & 1.677 & 8.825 & 47.672 & 2.672 & 14.066 & 33.961 \\
\hline 3 & 1.565 & 8.237 & 55.909 & 1.565 & 8.237 & 55.909 & 2.572 & 13.537 & 47.498 \\
\hline 4 & 1.316 & 6.929 & 62.838 & 1.316 & 6.929 & 62.838 & 2.391 & 12.584 & 60.082 \\
\hline 5 & 1.138 & 5.989 & 68.827 & 1.138 & 5.989 & 68.827 & 1.662 & 8.745 & 68.827 \\
\hline 6 & 0.762 & 4.012 & 72.839 & & & & & & \\
\hline 7 & 0.687 & 3.618 & 76.457 & & & & & & \\
\hline 8 & 0.618 & 3.254 & 79.712 & & & & & & \\
\hline 9 & 0.587 & 3.091 & 82.803 & & & & & & \\
\hline 10 & 0.508 & 2.672 & 85.475 & & & & & & \\
\hline 11 & 0.499 & 2.625 & 88.1 & & & & & & \\
\hline 12 & 0.461 & 2.425 & 90.524 & & & & & & \\
\hline 13 & 0.397 & 2.089 & 92.613 & & & & & & \\
\hline
\end{tabular}




\begin{tabular}{llll}
\hline 14 & 0.324 & 1.706 & 94.319 \\
\hline 15 & 0.272 & 1.433 & 95.752 \\
\hline 16 & 0.264 & 1.39 & 97.142 \\
\hline 17 & 0.214 & 1.128 & 98.269 \\
\hline 18 & 0.198 & 1.044 & 99.313 \\
\hline 19 & 0.13 & 0.687 & 100 \\
\hline
\end{tabular}

Factor Analysis- Communalities

The extent to which the five factors the account for the variance 17 variables is explained by the $\mathrm{R}^{2}$ values in the form of communalities shown in Table 5 . The variables having communalities less than 0.40 were dropped as their contribution to the underlying factor is negligible.

Table 5

Factor Analysis- Communalities

\begin{tabular}{lll}
\hline Variables & Initial & Extraction \\
\hline $\begin{array}{l}\text { I think that group work is a good idea. I enjoy taking part in group } \\
\text { work. }\end{array}$ & 1.000 & .779 \\
\hline $\begin{array}{l}\text { I think that I will learn more about the subject matter working in a } \\
\text { group than if I worked alone (or on my own). }\end{array}$ & 1.000 & .747 \\
\hline $\begin{array}{l}\text { Activities in group work are interesting and help me to understand the } \\
\text { subject matter better. }\end{array}$ & 1.000 & .607 \\
\hline Group activities make me active in the class. & 1.000 & .648 \\
\hline I feel confident to answer the questions in class. & 1.000 & .706 \\
\hline I feel motivated and fully committed in my class. & 1.000 & .673 \\
\hline A group grade is not fair. & 1.000 & .667 \\
\hline I learn better from group interaction than lecture. & 1.000 & .690 \\
\hline The lecturer is enthusiastic about the task of lecturing. & 1.000 & .708 \\
\hline It develops my communication abilities with my instructor. & 1.000 & .656 \\
\hline Lecturer designs group activities as appropriate, useful and interesting. & 1.000 & .746 \\
\hline The Lecturer has a good control over the class. & 1.000 & .692 \\
\hline Lecturer probes students understanding of material. & 1.000 & .718 \\
\hline Group activities help me in knowing my peers in class. & 1.000 & .645 \\
\hline It develops my communication abilities with my peers. & 1.000 & .626 \\
\hline It gives me chance to share ideas with others. & 1.000 & .659 \\
\hline Group members do not respect my opinion. & 1.000 & .677 \\
\hline Working in groups prepares us for real teamwork for our future career. & 1.000 & .762 \\
\hline $\begin{array}{l}\text { Working in groups allows us to know each other's experiences, their } \\
\text { learning skills, their cultures, and behavior. }\end{array}$ & 1.000 & .671 \\
\hline
\end{tabular}

Factor Analysis- Rotated Component Matrix

Varimax Rotation method with Kaiser Normalization is adapted to redistribute the factor loadings so that each variable precisely measure one factor as shown in Table 5. Our 19 variables were reduced to five core factors. The factor 'Learning experience' includes seven variables explaining students interest in group activities, learning methods in groups, design of group activities, level of motivation, interactions and commitment to learning. The Factor "Peer Experience" narrates four variables namely explaining their 
experience with their peers in group activities. The third factor includes three variables that explain the role of the instructor in managing the group activities. Factor 4 includes 3 variables explaining the development of student's collaborative skills while learning in groups. The last factor includes two variables that measure student's obstructive viewpoints towards group activities. The detailed result of factor analysis is illustrated in Table 6.

Table 6

Rotated Component Matrix ${ }^{\mathrm{a}}$

\begin{tabular}{|c|c|c|c|c|c|}
\hline \multirow{2}{*}{ Variables } & \multicolumn{5}{|c|}{ Component } \\
\hline & 1 & 2 & 3 & 4 & 5 \\
\hline $\begin{array}{l}\text { I think that group work is a good idea. I enjoy taking part in } \\
\text { group work. }\end{array}$ & .791 & & & & \\
\hline $\begin{array}{l}\text { I think that I will learn more about the subject matter working in } \\
\text { a group than if I worked alone (or on my own). }\end{array}$ & .724 & & & & \\
\hline I learn better from group interaction than lecture. & 692 & & & & \\
\hline Group activities make me active in the class. & .653 & & & & \\
\hline $\begin{array}{l}\text { Activities in group work are interesting and help me to } \\
\text { understand the subject matter better. }\end{array}$ & .580 & & & & \\
\hline I feel motivated and fully committed in my class. & .578 & & & & \\
\hline $\begin{array}{l}\text { Lecturer designs group activities as appropriate, useful and } \\
\text { interesting. }\end{array}$ & .574 & & & & \\
\hline Group activities help me in knowing my peers in class. & & .766 & & & \\
\hline It develops my communication abilities with my peers. & & .709 & & & \\
\hline It gives me chance to share ideas with others. & & .576 & & & \\
\hline I feel confident to answer the questions in class. & & .565 & & & \\
\hline Lecturer has a good control over the class. & & & .772 & & \\
\hline Lecturer is enthusiastic about the task of lecturing. & & & .701 & & \\
\hline Lecturer probes students understanding of material. & & & .653 & & \\
\hline It develops my communication abilities with my instructor. & & & & .740 & \\
\hline $\begin{array}{l}\text { Working in groups prepares us for real teamwork for our future } \\
\text { career. }\end{array}$ & & & & .688 & \\
\hline $\begin{array}{l}\text { Working in groups allows us to know each other's experiences, } \\
\text { their learning skills, their cultures and behavior. }\end{array}$ & & & & .677 & \\
\hline A group grade is not fair. & & & & & .808 \\
\hline Group members do not respect my opinion. & & & & & .576 \\
\hline $\begin{array}{l}\text { Extraction Method: Principal Component Analysis. } \\
\text { Rotation Method: Varimax with Kaiser Normalization. }\end{array}$ & & & & & \\
\hline
\end{tabular}

\section{Scale Reliability Test}

The core factors were tested for reliability of its coefficient that how close the variables included explain a core factor. A reliability coefficient of 0.70 or higher considered acceptable in social science researches. The results in Table 7 show that the alpha coefficient for the four factors has high internal consistency, except the last factor. 
Table 7

$\underline{\text { Scale Reliability Test Results and Factor Scores }}$

\begin{tabular}{lccccccc}
\hline Factors & $\mathrm{N}$ & Minimum & Maximum & Mean & $\begin{array}{l}\text { Std. } \\
\text { Deviation }\end{array}$ & $\begin{array}{l}\text { Cronbach's } \\
\text { Alpha }\end{array}$ & $\begin{array}{l}\text { N of } \\
\text { Items }\end{array}$ \\
\hline Learning Experience & 97 & 1.43 & 5.00 & 4.2077 & .70561 & .883 & 7 \\
\hline Peer Experience & 97 & 1.75 & 5.00 & 4.2887 & .61486 & .747 & 4 \\
\hline Role of Instructor & 97 & 1.00 & 5.00 & 4.2749 & .66495 & .708 & 3 \\
\hline $\begin{array}{l}\text { Collaborative skills } \\
\text { development }\end{array}$ & 97 & 2.00 & 5.00 & 4.2577 & .68466 & .777 & 3 \\
\hline $\begin{array}{l}\text { Obstructive viewpoints } \\
\text { toward groups }\end{array}$ & 97 & 1.00 & 5.00 & 3.6289 & .78155 & .337 & 2 \\
\hline
\end{tabular}

The output from table 7 identifies the core factor that influences students participation through group activities is greatly influenced by the peers included in each group. Kinds of literature have stressed peer learning to be a successful venture when it comes to improving students' academic and social cognitive skills. From the viewpoint of students' dynamics, peer learning promotes student relationships and aid students to foster a preeminent multicultural understanding and compliance (Wessel, 2015). The second eminent factor that influences students' participation is the role of instructor in assigning the groups, designing the appropriate activities and the effective management of groups to direct towards the achievement of course intended learning outcomes. Collaborative skills development while learning in groups is the third factor that influences student's attitude in large classes. Students from diverse knowledge, cultural and informational background communicate and discuss and draw conclusions freely in groups. Students gain information from different disciplines develops shared responsibility and also facilitates independent learning. The least influencing factor is the student's obstructive viewpoints towards group activities in large classes as the students well-perceived the introduction of group activities in large classes.

\section{CONCLUSION AND RECOMMENDATIONS}

This action research was undertaken to improve student participation through group activities in large classes. The results of observation indicated that the students' participation increases with group activity strategy. The increased students' participation had an impact on their academic achievement. The empirical results clearly indicated that the average scores of students had increased from 2.75 to 7.24 after the introduction of group activities. The students also well perceived group activity strategy as they found it interesting and useful and it had changed the way they learned the course. The empirical results of factor analysis identified the core factor that influenced students participation through group activities was greatly influenced by the peers included in each group. Overall the group activity strategy has proved effective and successful in promoting students participation and academic achievement in large classes.

A number of feasible recommendations could be derived from the findings. Group work has to be considered as one of the course assessments with grades to motivate the students and to be included in the course outline. Physical layout spaces in large classes have to be modified to facilitate group learning. Future studies could introduce flipped classroom activities in groups which will widen the students' interaction even outside 
the classroom. There are few limitations during the study like time constraint and the possibility of the perception bias in collecting the observation results by the researcher. By conducting this action research, the researcher reflected on own teaching practice and this self-reflection made her realize her big role in creating an effective learning environment now and in the future.

\section{REFERENCES}

Biggs, J., \& Tang, C. (2011). Teaching for Quality Learning at University. Fourth ed. New York: McGraw Hill.

Biggs, J. (2003). Changing University Teaching' In Teaching for Quality Learning at University London, 2nd Edition, Society for Research into Higher Education and Open University Press. Quoted in Kasa, Y. (2016) Improving Student's Participation in the Classroom in Chemistry Freshman Students at Assosa University: An Experimental Action Research. International Journal of Education, Culture and Society, 1(1), 5-10.

Brooks, D. (1984). Alternatives to Traditional Lecturing. Journal of Chemical Education, 61(10), 858-859.

Burke, A. (2011). Group Work: How to Use Groups Effectively. The Journal of Effective Teaching, 11(2), 87-95.

Carpenter, J. (2006). Effective Teaching Methods for Large Classes. Journal of Family \& Consumer Sciences Education, 24(2), 13-23.

Dowson, F., \& Dowson, M. (2009). Group work Questionnaire [Internet], Available from: http://new.learnhigher.ac.uk/resources/files/group\%20work\%20study\%20200809.doc [Accessed 12 Feb 2018].

Hassanien, A. (2007). A qualitative student evaluation of group learning in higher education. Higher Education in Europe, 32(2), 135-150. Quoted in Taqi, H and AlNouh, N. (2014) Effect of Group Work on EFL Students' Attitudes and Learning in Higher Education. Journal of Education and Learning; 3(2), 52-65.

Hendry, G. D., \& Davy, H. P. (2005). Independent student study groups. Medical Education. 39, 672-679. Quoted in Taqi,H and Al-Nouh, N. (2014) Effect of Group Work on EFL Students' Attitudes and Learning in Higher Education. Journal of Education and Learning; 3(2), 52-65.

Hood, L. (2007). Some Class Participation Techniques for Larger Classes [Internet], Available from: https://www.schreyerinstitute.psu.edu/pdf/2011-10-13-10430Class_Participation_Techniques.pdf [Accessed 12 Feb 2018].

Kasa, Y. (2016). Improving Student's Participation in the Classroom in Chemistry Freshman Students at Assosa University: An Experimental Action Research. International Journal of Education, Culture and Society, 1(1), 5-10.

Marcus, S. (1997). Large Class Size: Strategies for Success. The English Teacher, 26, December, 1-13. 
Meijer, P., Verloop, N., \& Beijaard, D. (2002). Multi-Method Triangulation in a Qualitative Study on Teachers' Practical Knowledge: An Attempt to Increase Internal Validity. Quality \& Quantity, 36, 145-167.

Race, P. (2014). Making Learning Happen: A Guide for Post-Compulsory Education. 3rd ed. London, SAGE Publications.

Renaud, S., Tannenbaum, E., \& Stantial, P. (2007). Student-Centered Teaching in Large Classes with Limited Resources. English Teaching Forum, 3, November, 12-18.

Smith, B. (1997). Lecturing to Large Groups. Special 1. London, SEDA.

Smith, D. (1992). Encouraging students' participation in large classes: A modest proposal. Teaching Sociology, 20(4), 337-339.

Smith, K. (2000). Going deeper: Formal small-group learning in large classes. New Directions for Teaching and Learning, 81, 25-46.

Sofroniou, A., \& Poutos, K. (2016). Investigating the Effectiveness of Group Work in Mathematics. Education Science, 6(30), 1-15.

Taqi, H., \& Al-Nouh, N. (2014). Effect of Group Work on EFL Students' Attitudes and Learning in Higher Education. Journal of Education and Learning; 3(2), 52-65.

Tesfaye, S., \& Berhanu, K. (2015). Improving Students' Participation in Active Learning Methods: Group Discussions, Presentations and Demonstrations: A Case of Madda Walabu University Second Year Tourism Management Students of 2014. Journal of Education and Practice, 22(6), 29-32.

Wade, R. (1994). Teacher education students' views on classroom discussion: Implications for fostering critical reflection. Teaching and Teacher Education, 10, 231243.

Wessel, A. (2015). Peer Learning Strategies in the Classroom. Journal on Best Teaching Practices. 2(1), 14-16.

Zhang, D. (2005) Action Research on Large Class Activity [Internet], Available from: http://users.monash.edu.au/ dengs/teaching/GCHE/Action\%20Research\%20on\%20Larg e\%20Class\%20Activity.pdf [Accessed 26 September 2017].

Zhenhui, R. (2001) Advantages of Group Centered Learning in Large Classes. [Internet], Available from: http://www.nzdl.org/gsdl/collect/literatu/index/assoc/HASH01ac.dir/doc.pdf [Accessed $12 \mathrm{Feb} 2018]$. 